\title{
Psychological impact of COVID 19 pandemic on practicing Egyptian ophthalmologists
}

Faried M. Wagdy ${ }^{1}$, Tharwat H. Mokbel ${ }^{2}$, Hadeer A. El Shebshery ${ }^{3}$, Zeinab A. Kasemy ${ }^{4}$, Abd-Almonem Alhessy ${ }^{2}$, Dina Abd Elfattah².

1- Department of Ophthalmology, Faculty of medicine, Menoufiya University, Egypt

2- Mansoura Ophthalmic Center, Mansoura University

3- Ophthalmology resident doctor at ministry of health, Tala Hospital, Menoufiya government, Egypt.

4- Department of Public Health and Community medicine, Faculty of Medicine - Menoufiya University, Egypt

Correspondence to: Faried M. Wagdy. Department of Ophthalmology, Faculty of medicine, Menoufiya University, Egypt. Email: fariedwagdy1976@gmail.com

Received: 2/2/2021, Accepted: 11/3/2021, Published online:11/3/2021

EJO(MOC) 2021;1:40-54.

Short title: Psychological impact of COVID 19 pandemic on ophthalmologists

Abstract:

Aim: To assess the psychological impact of the COVID 19 pandemic on practicing ophthalmologists in Egypt.

Methods: A cross-sectional study with convenience sampling technique was conducted on 300 ophthalmologists from July to September 2020 through personal interview and online questionnaires including data about $\mathrm{i}$. Characteristics of the participants, ii. Medical and surgical procedures that have risk for transmission of COVID 19 and usage of protective precautions, iii. Generalized Anxiety Disorder Assessment (GAD), and iv. Patient Health Questionnaire-9 (PHQ-9).

Results: The study was conducted on 300 ophthalmologists distributed as 138 were male(46\%) and162 were females(54\%). Symptoms of anxiety were reported in 93.3\% while depression symptoms were reported among(72.7\%) of the participants. Anxiety significantly increased among ophthalmologists who are $\operatorname{married}(\mathrm{p}=0.001)$, being resident doctor $(\mathrm{P}=0.001)$, having been infected with COVID-19(P=0.034) and knowing a colleague in the same specialty infected with COVD-19(0.001). Severe anxiety was significantly reported among those took all precautions against COVID-19( $\mathrm{p}=0.004)$ and at the same time these precaution were uncomfortable $(p=0.001)$ where usage of face shield or slit lamp partition makes the examination difficult $(p=0.029,0.001$ respectively). Also severe anxiety was reported among those who decided to continue all infection control precaution incase COVID-19 continues $(\mathrm{p}=0.001)$. Depression symptoms were significant among ophthalmologists who are married $(\mathrm{p}=0.001)$, being resident doctor $(\mathrm{P}=0.001)$, having been infected with COVID$19(\mathrm{P}=0.004)$ and knowing a colleague in the same specialty infected with COVD-19(P=0.003). Severe depression was significantly reported among those considered precautions taken against COVD-19 were uncomfortable $(\mathrm{p}=0.018)$ particularly slit lamp partition $(\mathrm{P}=0.002)$, and also those used face mask $>2$ hours, took all precautions and decided to follow the same precautions if COVID-19 still present $(\mathrm{p}=0.041,0.018,0.030$ respectively).

Conclusion: COVID-19 pandemic had a great effect on young aged, married and resident, who taken much precautions and who are previously infected or knew a colleague infected with COVID-19. The psychological needs

Egyptian Journal of Ophthalmology, a publication of Mansoura Ophthalmic Center.

Address: Mansoura Ophthalmic Center, Mansoura University, Mansoura, Egypt.

Website: https://ejomos.journals.ekb.eg

Tel. 0020502202064.

Fax. 0020502202060.

E-mail: ejo@mans.edu.eg 
for ophthalmologists in particular and health-care providers in general should be addressed appropriately during the pandemic. Effort should be made to established psychological support unit, especially for high risk healthcare providers.

Keywords: COVID-19, Anxiety and depression among Ophthalmologists, Healthcare workers

\section{Introduction:}

COVID-19 outbreak has affected millions globally. It not only affects the physical health of those infected by the virus, but also causes psychological impact, such as stress, anxiety, depression, insomnia, denial, anger, and fear. Psychological implications can be attributed to direct or indirect effects of the illness on livelihood and living conditions. ${ }^{1}$ The virus was first seen in China,countries in the European and American continents are the most affected.

The first case in Egypt was reported on 14 February 2020. Various precautions began being adopted as the number of cases increased, and a wide range of measuresare still in place. As of 1 October 2020, the total numberof reported cases in Egypt was 103198, with 5930 deaths $^{2}$.

Asymptomatic transmission of the disease causes fear and anxiety. In addition, lack of personal protective equipment (PPE) and social care professionals are associated factors ${ }^{3}$. The impact of COVID-19 on mental health of residents and health professionals in China is well studied ${ }^{4-6}$. In a study to assess mental health status of medical and nursing staff in Wuhan, it was found that $36.9 \%$ had subthreshold mental health disturbances, including 6.2\% with severe disturbances?

COVID-19 has not only affected the mental health of frontline healthcare workers, but also other health care professionals who are not in the forefront, such as ophthalmologists. However, there are no reports on the mental health of other health care professionals who are not directly involved in COVID care. Ophthalmology as a specialty is at an increased risk as most of the procedures bring ophthalmologists in close contact with the patient's eyes and face. Various parts of the patient's face touch the ophthalmic equipment, thus increasing the risk of spread of infection through aerosolized particles from respiratory droplet and contact $^{8}$. There are also reports of SARS-CoV-2 identified in tears and conjunctival swabs, thus putting ophthalmologists at a risk of acquiring the infection ${ }^{9-13}$.

In a survey among health care professionals in Moorfield's Eye hospital, London, $80 \%$ of the respondents felt that they are at high risk of COVID19 transmission ${ }^{14}$. In addition, ophthalmologists might be the first to encounter COVID-19 patients presenting with keratoconjunctivitis as the only and initial presenting symptom ${ }^{15}$. It is well known that stigmatization of health care professionals is very common during an epidemic ${ }^{16}$. Hence, it is vital that we understand the impact of COVID-19 on the mental health of health care professionals, and design additional global strategies to provide appropriate mental health care $^{17}$. The aim of this study was to assess the psychological impact of the COVID 19 pandemic on practicing ophthalmologists in Egypt during lockdown using a validated mental health questionnaire.

\section{Methods:}

A cross-sectional study with convenience sampling technique was conducted on 300 ophthalmologists from July to September 2020 through personal interview and online questionnaires. Four questionnaires were used and they involved questions about:

I. Characteristics of the participants; Age, gender, working days, etc. 
II. Medical and surgical procedures that have risk for transmission of COVID 19 infection and usage of protective precautions: e.g. The instruments or medical devices that have more risk to transfer COVID-19 e, the surgical operation that have more risk to transfer COVID-19,

III. Generalized Anxiety Disorder Assessment (GAD-

7) is used as a screening tool and severity measure for generalized anxiety disorder (GAD). The GAD-7 score is calculated by assigning scores of $0,1,2$, and 3 , to the response categories of 'not at all', 'several days', 'more than half the days', and 'nearly every day', respectively, and adding together the scores for the seven questions. Scores of 5,10, and 15 are taken as the cut-off points for mild, moderate and severe anxiety, respectively. When used as a screening tool, further evaluation is recommended when the score is 10 or greater ${ }^{18}$. Using the threshold score of 10, the GAD-7 has a sensitivity of $89 \%$ and a specificity of $82 \%$ for GAD. It is moderately good at screening three other common anxiety disorders - panic disorder (sensitivity $74 \%$, specificity $81 \%$ ), social anxiety disorder (sensitivity $72 \%$, specificity $80 \%$ ) and post-traumatic stress disorder (sensitivity 66\%, specificity $81 \%)^{19}$.

IV.Patient Health Questionnaire-9 (PHQ-9) is a selfreport measure that is used to assess the severity of depression over the prior 2 weeks. Response to the nine questions are graded as 0 (not at all), 1 (several days), 2 (more than half the days), and 3 (nearly every day). The total score of PHQ-9 that categorizes depression is as follows: minimal/no depression (0-4), mild depression (5-9), moderate depression (10-14), or severe depression (15-21) 20.

The questionnaires were chosen based on being easy to understood, less time taken and to the point and all these criteria were assessed through a pilot study where the questionnaires were pretested on 20 participants ( 15 online and 5 personal interviews) to ensure its validity and feasibility. The online questionnaires were translated to help the participants to share. The personal interviews were interviewer-based questionnaires with the same language used for the online questionnaires to avoid any bias concerning understanding of the questions. After analysis of the questionnaires' feedback some modifications were performed such as reduction of its questions to avoid annoying participants by too much questions. The online recipients could forward the link to friends, in a snowball strategy. Anxiety and depression questionnaires had been previously validated.

\section{Statistical analysis:}

Data were analyzed using SPSS V.22. Descriptive statistics in the form of percentage (\%), mean $\pm \mathrm{SD}$, median and range were performed. Chi-square $\left(\chi^{2}\right)$ and Fisher's exact test were used for qualitative data. Odds ratios (OR) were used to assess risk of exposure ( $\mathrm{OR}=1$ nil, $\mathrm{OR}>1$ Risky and $\mathrm{OR}<1$ Protective). $\mathrm{P}$ value less than 0.05 was set as statistically significant.

\section{Results:}

The study was conducted on 300 ophthalmologists distributed as 138 were male (46\%) and162 were female (54\%). The mean age was $36.1 \pm 6.64$ years (range 25-58years). The participants were in varying levels in ophthalmology practice; the majority were residents $(\mathrm{n}=160,53.3 \%)$, and the remaining were fellows $(\mathrm{n}=90,30.0 \%)$, and consultants $(\mathrm{n}=50$, $16.7 \%)$. According to number of working hours/days, 284 ophthalmology physicians (82.7\%) were working $(>3)$ hours/day and $48.7 \%$ were working more than 3 days a week. The incidence of COVID-19 infection was reported among $17.3 \%$ of the studied ophthalmologists $(17.3 \%)$ while $65 \%$ of the ophthalmologists reported knowledge of colleague being infected with COVID-19. The flow rate of patient duringCOVID-19 pandemic decreased as 
reported by $65.7 \%$ of ophthalmologists which was mainly due to fear of getting infected from doctors and restriction due to country rules $(37.6 \%)$.(Table 1)

Assessment of medical and surgical procedures that have risk for transmission of COVID 19 infection and usage of protective precautions revealed that $41.3 \%$ of the physicians spent 5 minutes for medical examination of the patients. For instruments that had more risk to transfer COVID-19, $66.3 \%$ of the physicians said both medical instruments and surgical instruments were risky instruments. Direct ophthalmoscope and surgical operation without surgical microscope were the most risky as reported by $85.7 \%$ and $90 \%$ of the physicians respectively while $61.7 \%$ said LASIK was the least risky surgical procedure to transfer COVID-19. When asking about the precautions taken, $46 \%$ have been taken Precautions of applying sterilizer, wearing mask, social distance and, Slit lamp partition. But $60 \%$ of them said these precautions were not comfortable. Wearing mask continually for more than 2 hours was reported by $76.3 \%$. Face shield and slit lamp partitions were reported to be comfortable by $58.7 \%$ and $86.7 \%$ respectively. While $72.7 \%$ of ophthalmology physicians felt upset $80.7 \%$ will follow the same precautions if COVID-19 present till end of year 2020.(Table 2)

Symptoms of anxiety were reported in $93.3 \%$ of the participants distributed as mild symptoms (27\%), moderate symptoms (37\%), and severe symptoms (29.3\%). For depression symptoms, (72.7\%) of the participants exhibited symptoms of depression, distributed as mild symptoms (36\%), moderate symptoms, $(18.7 \%)$ and severe symptoms (18.0\%).(Table 3)
Anxiety significantly increased among ophthalmologists who are married $(\mathrm{p}=0.001)$, being resident doctor $(\mathrm{P}=0.001)$, having been infected with COVID-19 ( $\mathrm{P}=0.034)$ and knowing a colleague in the same specialty infected with COVD-19 (0.001).(Table 4)

Severe anxiety was significantly reported among with those took all precautions against COVID-19 $(\mathrm{p}=0.004)$ and at the same time these precaution were uncomfortable $(\mathrm{p}=0.001)$ where usage of face shield or slit lamp partition makes the examination difficult $(\mathrm{p}=0.029,0.001$ respectively). Also severe anxiety was reported among those who decided to continue all infection control precaution incase COVID-19 continues $(p=0.001)$ what makes them feel upset $(\mathrm{p}=0.004) .($ Table 5$)$

There was no significant difference regarding depression grades in relation to age, sex or working hours $(\mathrm{P}>0.05)$ but depression were significant among ophthalmologists who are married $(\mathrm{p}=0.001)$, being resident doctor $(\mathrm{P}=0.001)$, having been infected with COVID-19 ( $\mathrm{P}=0.004)$ and knowing a colleague in the same specialty infected with COVD-19 $(\mathrm{P}=0.003)$. (Table 6)

Severe depression was significantly reported among those considered precautions taken against COVD-19 were uncomfortable $(\mathrm{p}=0.018)$ particularly slit lamp partition ( $\mathrm{P}=0.002)$ also those felt upset duringCOVD-19 $(\mathrm{P}=0.001)$. There was no significant difference regarding usage of face shield $(\mathrm{P}>0.05)$. At the same time those used face mask $>2$ hours, took all precautions and decided to follow the same precautions if COVID-19 still present.(Table 7) 
Table 1: Demographic data of the studied group

\section{Studied group}

Variables

$\mathbf{n}=\mathbf{3 0 0}$

Age/years

Mean \pm SD

$36.1 \pm 6.64$

Min - Max

$25-58$

$\leq 30$ years

$167(55.7)$

$>30$ years

133(44.3)

\section{Gender}

Male

Female

162(54.0)

Marital status

Married

207(69.0)

Single

93(31.0)

Level

Resident

$160(53.3)$

Fellow

90(30.0)

Consultant

$50(16.7)$

Number of working hours / day

1 - 2 hours

12(4.00)

2 - 3 hours

$>3$ hours

Days of work / week

One day

Two days

53(17.7)

Three days

90(30.0)

More than 3 days

146(48.7)

Previously infected with COVID-19

Yes

No

248(82.7)

Knowing a specialty colleague infected with COVD-19

Yes

No

$105(35.0)$ 
Table 2: Frequency distribution of medical and surgical procedures that have risk for transmission of COVID 19 infection and usage of protective precautions.

\begin{tabular}{|c|c|c|}
\hline \multirow[b]{2}{*}{ Variables } & \multicolumn{2}{|c|}{ Studied group $n=300$} \\
\hline & & \\
\hline \multicolumn{3}{|l|}{ Average time for medical examination } \\
\hline 2 minutes & 8 & 2.70 \\
\hline 5 minutes & 124 & 41.3 \\
\hline 10minutes & 114 & 38.0 \\
\hline$>10$ minutes & 54 & 18.0 \\
\hline \multicolumn{3}{|c|}{ The instruments that have more risk to transfer COVID-19 } \\
\hline Medical instruments & 99 & 33.0 \\
\hline Surgical instruments & 2 & 0.70 \\
\hline Both & 199 & 66.3 \\
\hline \multicolumn{3}{|c|}{ The medical devices that have more risk to transfer COVID-19 } \\
\hline Direct ophthalmoscope & 257 & 85.7 \\
\hline Indirect ophthalmoscope & 3 & 1.00 \\
\hline Slit lamp & 40 & 13.3 \\
\hline \multicolumn{3}{|c|}{ The surgical operation that have more risk to transfer COVID-19 } \\
\hline With surgical microscope & 28 & 9.30 \\
\hline Without surgical microscope & 272 & 90.7 \\
\hline \multicolumn{3}{|c|}{ Less risky surgical procedure to transfer COVID-19 } \\
\hline LASIK & 185 & 61.7 \\
\hline LASIK and Phako & 57 & 19.0 \\
\hline Oculoplastic surgery & 13 & 4.30 \\
\hline All of the above & 45 & 15.0 \\
\hline \multicolumn{3}{|l|}{ Precautions taken } \\
\hline Sterilizer and mask & 70 & 23.3 \\
\hline Sterilizer and mask and social distance & 83 & 27.7 \\
\hline Slit lamp partition & 9 & 3.00 \\
\hline All & 138 & 46.0 \\
\hline \multicolumn{3}{|l|}{ Are these precautions } \\
\hline Comfortable & 120 & 40.0 \\
\hline Uncomfortable & 180 & 60.0 \\
\hline \multicolumn{3}{|l|}{ The continuous period of using face mask } \\
\hline$<1$ hour & 60 & 20.0 \\
\hline $1-2$ hours & 11 & 3.70 \\
\hline$>2$ hours & 229 & 76.3 \\
\hline \multicolumn{3}{|l|}{ Usage of face shield } \\
\hline Comfortable & 176 & 58.7 \\
\hline Make the examination difficult & 124 & 41.3 \\
\hline \multicolumn{3}{|l|}{ Usage of slit lamp partition } \\
\hline Comfortable & 40 & 13.3 \\
\hline Uncomfortable & 260 & 86.7 \\
\hline \multicolumn{3}{|l|}{ This period of COVID-19 makes you feel } \\
\hline Upset & 239 & 79.7 \\
\hline Not disturbed & 61 & 20.3 \\
\hline \multicolumn{3}{|l|}{ What to do if COVID-19 continues? } \\
\hline Follow the same precautions & 242 & 80.7 \\
\hline Return to usual work before COVID 19 & 8 & 2.7 \\
\hline I don't know & 50 & 16.7 \\
\hline
\end{tabular}


Table 3: Anxiety and depression among the studied group

\begin{tabular}{|c|c|c|}
\hline \multirow[b]{2}{*}{ Variables } & \multicolumn{2}{|c|}{ Studied group $n=300$} \\
\hline & no & $\%$ \\
\hline \multicolumn{3}{|c|}{ Anxiety symptoms } \\
\hline Yes & 280 & 93.3 \\
\hline No & 20 & 6.70 \\
\hline \multicolumn{3}{|c|}{ Anxiety grades } \\
\hline No & 20 & 6.70 \\
\hline Mild & 81 & 27.0 \\
\hline Moderate & 111 & 37.0 \\
\hline Severe & 88 & 29.3 \\
\hline \multicolumn{3}{|c|}{ GAD 7 score } \\
\hline Mean \pm SD & $7.35 \pm 5.42$ & \\
\hline Min - Max & $0-21$ & \\
\hline \multicolumn{3}{|c|}{ Depression symptoms } \\
\hline Yes & 218 & 72.7 \\
\hline No & 82 & 27.3 \\
\hline \multicolumn{3}{|c|}{ Depression grades } \\
\hline No & 82 & 27.3 \\
\hline Mild & 108 & 36.0 \\
\hline Moderate & 56 & 18.7 \\
\hline Severe & 54 & 18.0 \\
\hline \multicolumn{3}{|l|}{ PHQ score } \\
\hline Mean \pm SD & $8.99 \pm 6.39$ & \\
\hline Min - Max & $0-27$ & \\
\hline
\end{tabular}

Data are presented as $\mathrm{n}(\%)$ 
Table 4: Relation between anxiety grades and demographic data of the studied participants

\begin{tabular}{|c|c|c|c|c|c|c|}
\hline \multirow[b]{2}{*}{ Variables } & \multicolumn{4}{|c|}{ Anxiety grades } & \multirow[b]{2}{*}{$\mathrm{X} 2$} & \multirow[b]{2}{*}{ P value } \\
\hline & $\begin{array}{l}\text { No } \\
(\mathrm{n}=\mathbf{2 0})\end{array}$ & $\begin{array}{l}\text { Mild } \\
(\mathrm{n}=\mathbf{8 1})\end{array}$ & $\begin{array}{l}\text { Moderate } \\
(\mathrm{n}=111)\end{array}$ & $\begin{array}{l}\text { Severe } \\
(\mathrm{n}=88)\end{array}$ & & \\
\hline \multicolumn{7}{|l|}{ Age/years } \\
\hline$\leq 30$ years & $15(75.0)$ & $43(53.1)$ & $60(54.1)$ & $49(55.7)$ & 3.36 & 0.339 \\
\hline$>30$ years & $5(25.0)$ & $38(46.9)$ & $51(45.9)$ & $39(44.3)$ & & \\
\hline \multicolumn{7}{|l|}{ Gender } \\
\hline Male & $12(60.0)$ & $36(44.4)$ & $52(46.8)$ & $38(43.2)$ & 1.97 & 0.579 \\
\hline Female & $8(40.0)$ & $45(55.6)$ & $59(53.2)$ & $50(56.8)$ & & \\
\hline \multicolumn{7}{|l|}{ Marital status } \\
\hline Married & $12(60.0)$ & $31(38.3)$ & $88(79.3)$ & $76(86.4)$ & 54.4 & $0.001 *$ \\
\hline Single & $8(40.0)$ & $50(61.7)$ & $23(20.7)$ & $12(13.6)$ & & \\
\hline \multicolumn{7}{|l|}{ Level } \\
\hline Resident & $5(25.0)$ & $30(37.5)$ & $66(59.5)$ & $59(67.0)$ & & \\
\hline Fellow & $3(15.0)$ & $33(40.7)$ & $30(27.0)$ & $24(27.3)$ & 47.1 & $0.001 *$ \\
\hline Consultant & $12(60.0)$ & $18(22.2)$ & $15(13.5)$ & $5(5.70)$ & & \\
\hline \multicolumn{7}{|c|}{ Number of working hours / day } \\
\hline $1-2$ hours & $0(0.00)$ & $1(1.20)$ & $3(2.70)$ & $8(9.10)$ & & \\
\hline 2 - 3 hours & $1(5.00)$ & $9(11.1)$ & $16(14.4)$ & $14(15.9)$ & 11.6 & \\
\hline$>3$ hours & 19(95.0) & $71(87.7)$ & $92(82.9)$ & $66(75.0)$ & & 0.071 \\
\hline \multicolumn{7}{|c|}{ Days of work / week } \\
\hline One day & $0(0.00)$ & $3(3.70)$ & $5(4.50)$ & $3(3.40)$ & & \\
\hline Two days & $1(5.00)$ & $13(16.0)$ & $20(18.0)$ & $19(21.6)$ & 12.6 & 0.178 \\
\hline Three days & $3(15.0)$ & $21(25.9)$ & $35(31.5)$ & $31(35.2)$ & & \\
\hline More than 3 days & $16(80.0)$ & $44(54.3)$ & $51(45.9)$ & $35(39.8)$ & & \\
\hline \multicolumn{7}{|c|}{ Previously infected with COVID- } \\
\hline 19 & $19(17.1)$ & $8(9.90)$ & $19(17.1)$ & $23(26.1)$ & & \\
\hline Yes & $92(82.9)$ & $73(90.1)$ & $92(82.9)$ & $65(73.9)$ & 8.65 & $0.034 *$ \\
\hline \multicolumn{7}{|l|}{ No } \\
\hline \multicolumn{7}{|c|}{$\begin{array}{l}\text { Knowing a specialty colleague } \\
\text { infected with COVD-19 }\end{array}$} \\
\hline Yes & $15(75.0)$ & $42(51.9)$ & $71(64.0)$ & $70(79.5)$ & & \\
\hline No & $5(25.0)$ & $39(48.1)$ & $40(36.0)$ & $18(20.5)$ & 19.2 & $0.001 *$ \\
\hline
\end{tabular}

Data are presented as $\mathrm{n}(\%) *$ significant 
Table 5: Relation between anxiety grades and usage of protective precautions

\begin{tabular}{|c|c|c|c|c|c|c|}
\hline \multirow[b]{2}{*}{ Variables } & \multicolumn{4}{|c|}{ Anxiety grades } & \multirow[b]{2}{*}{$\mathbf{X} 2$} & \multirow[b]{2}{*}{$P$ value } \\
\hline & $\begin{array}{l}\text { No } \\
(\mathrm{n}=\mathbf{2 0})\end{array}$ & $\begin{array}{l}\text { Mild } \\
(\mathrm{n}=\mathbf{8 1})\end{array}$ & $\begin{array}{l}\text { Moderate } \\
(n=111)\end{array}$ & $\begin{array}{l}\text { Severe } \\
(\mathrm{n}=\mathbf{8 8})\end{array}$ & & \\
\hline \multicolumn{7}{|l|}{ Precautions taken } \\
\hline Sterilizer and mask & $9(45.0)$ & $21(25.9)$ & $23(20.7)$ & $17(19.3)$ & & \\
\hline Sterilizer and mask and social distance & $4(20.0)$ & $22(27.2)$ & $37(33.3)$ & $20(22.7)$ & & \\
\hline Slit lamp partition & $0(0.0)$ & $0(0.0)$ & $1(0.9)$ & $8(9.1)$ & 23.9 & $0.004 *$ \\
\hline All & $7(35.0)$ & $38(46.9)$ & $50(45.0)$ & 43(48.9) & & \\
\hline \multicolumn{7}{|l|}{ Are these precautions } \\
\hline Comfortable & $14(70.0)$ & $31(50.6)$ & $41(36.9)$ & $24(27.3)$ & 17.6 & $0.001 *$ \\
\hline Uncomfortable & $6(30.0)$ & $40(49.4)$ & $70(63.1)$ & $64(72.7)$ & & \\
\hline \multicolumn{6}{|l|}{ The continuous period of using face } & \\
\hline$<1$ hour & $3(15.0)$ & $19(23.5)$ & $23(20.7)$ & $15(17.0)$ & 6.83 & 0.337 \\
\hline $1-2$ hours & $15(75.0)$ & $59(72.8)$ & $87(78.4)$ & $68(77.3)$ & & \\
\hline \multicolumn{7}{|l|}{$>2$ hours } \\
\hline \multicolumn{7}{|l|}{ Usage of face shield } \\
\hline Comfortable & $13(65.0)$ & $58(71.6)$ & $57(51.4)$ & $48(54.5)$ & 8.98 & $0.029 *$ \\
\hline Make the examination difficult & $7(35.0)$ & $23(28.4)$ & $54(48.6)$ & $40(45.5)$ & & \\
\hline \multicolumn{7}{|l|}{ Usage of slit lamp partition } \\
\hline Comfortable & $7(35.0)$ & $18(22.2)$ & $10(9.00)$ & $5(5.70)$ & 19.9 & $0.001 *$ \\
\hline Uncomfortable & $13(65.0)$ & $63(77.8)$ & 101(91.0) & $83(94.3)$ & & \\
\hline $\begin{array}{l}\text { This period of COVID-19 makes y } \\
\text { feel }\end{array}$ & \multicolumn{5}{|c|}{ This period of COVID-19 makes you } & \\
\hline Upset & $16(80.0)$ & $31(38.3)$ & $12(10.8)$ & $2(2.30)$ & 83.9 & $0.001 *$ \\
\hline \multicolumn{7}{|l|}{ Not disturbed } \\
\hline \multicolumn{7}{|l|}{ What to do if COVID-19 continues? } \\
\hline Follow the same precautions & $14(70.0)$ & $71(87.7)$ & $89(80.2)$ & $68(77.3)$ & & \\
\hline Return to usual work before COVID 19 & $3(15.0)$ & $2(2.50)$ & $3(2.70)$ & $0(0.00)$ & & \\
\hline I don't know & $3(15.0)$ & $8(9.90)$ & $19(17.1)$ & $20(22.7)$ & 18.8 & $0.004 *$ \\
\hline
\end{tabular}

Data are presented as $\mathrm{n}(\%),{ }^{*}$ significant 
Table 6: Relation between depression grades and demographic data of the studied group

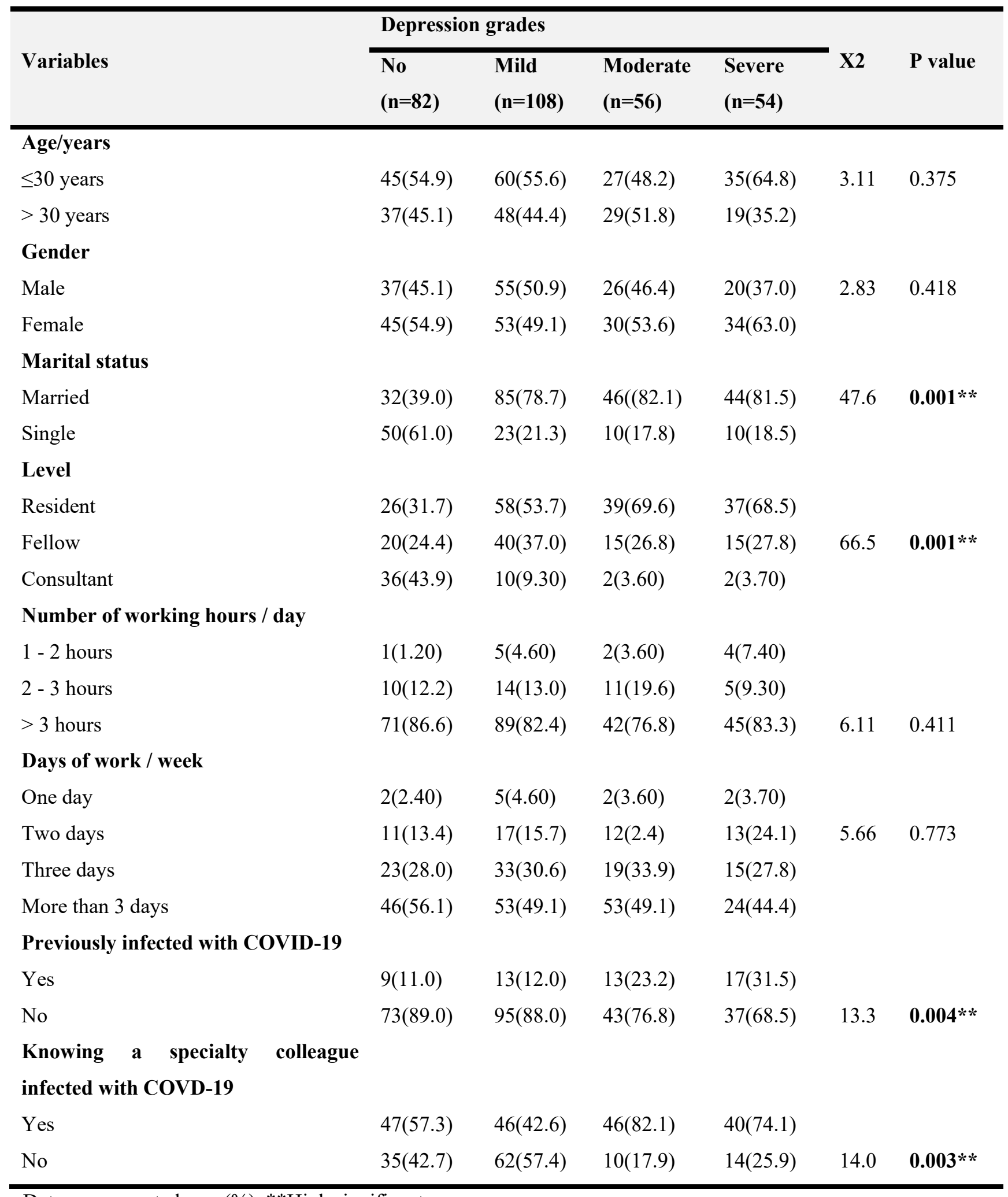

Data are presented as n (\%), **High significant 
Table 7: Relation between depression grades and usage of protective precautions

\begin{tabular}{|c|c|c|c|c|c|c|}
\hline \multirow[b]{2}{*}{ Variables } & \multicolumn{4}{|c|}{ Depression grades } & \multirow[b]{2}{*}{$\chi^{2}$} & \multirow[b]{2}{*}{ P value } \\
\hline & $\begin{array}{l}\text { No } \\
(n=82)\end{array}$ & $\begin{array}{l}\text { Mild } \\
(n=108)\end{array}$ & $\begin{array}{l}\text { Moderate } \\
(n=56)\end{array}$ & $\begin{array}{l}\text { Severe } \\
(n=54)\end{array}$ & & \\
\hline \multicolumn{7}{|l|}{ Precautions taken } \\
\hline Sterilizer and mask & $24(29.3)$ & $22(20.4)$ & $8(14.3)$ & $16(29.6)$ & & \\
\hline Sterilizer and mask and social distance & $25(30.5)$ & $32(29.1)$ & $16(28.6)$ & $10(18.5)$ & 20.0 & 0.018* \\
\hline Slit lamp partition & $0(0.0)$ & $1(0.9)$ & $3(5.40)$ & $5(9.30)$ & & \\
\hline All & $33(40.2)$ & $53(49.1)$ & $29(51.8)$ & $23(42.6)$ & & \\
\hline \multicolumn{7}{|l|}{ Are these precautions } \\
\hline Comfortable & $49(59.8)$ & $42(38.9)$ & $15(26.8)$ & $14(25.9)$ & 21.9 & $0.001 * *$ \\
\hline Uncomfortable & $33(40.2)$ & $66(61.1)$ & $41(73.2)$ & $40(74.1)$ & & \\
\hline \multicolumn{7}{|l|}{ The continuous period of using face } \\
\hline mask & $6(7.30)$ & $1(0.90)$ & $2(3.60)$ & $2(3.70)$ & & \\
\hline$<1$ hour & $14(17.1)$ & $30(27.8)$ & $11(19.6)$ & $5(9.30)$ & 13.1 & $0.041 *$ \\
\hline $1-2$ hours & $62(75.6)$ & $77(71.3)$ & $43(76.8)$ & $47(87.0)$ & & \\
\hline \multicolumn{7}{|l|}{$>2$ hours } \\
\hline \multicolumn{7}{|l|}{ Usage of face shield } \\
\hline Comfortable & $55(67.1)$ & $56(51.9)$ & $34(60.7)$ & $31(57.4)$ & 4.59 & 0.204 \\
\hline Make the examination difficult & $27(32.9)$ & $52(48.1)$ & $22(39.3)$ & $23(42.6)$ & & \\
\hline \multicolumn{7}{|l|}{ Usage of slit lamp partition } \\
\hline Comfortable & $21(25.6)$ & $8(7.40)$ & $6(10.7)$ & $5(9.30)$ & 15.1 & $0.002 * *$ \\
\hline Uncomfortable & $61(74.4)$ & $100(92.6)$ & $50(89.3)$ & $49(90.7)$ & & \\
\hline \multicolumn{7}{|l|}{ This period of COVID-19 makes you } \\
\hline feel & $42(51.2)$ & $90(83.3)$ & $54(96.4)$ & $53(98.1)$ & 62.9 & $0.001 * *$ \\
\hline Upset & $40(48.8)$ & $18(16.7)$ & $2(3.60)$ & $1(1.90)$ & & \\
\hline \multicolumn{7}{|l|}{ Not disturbed } \\
\hline \multicolumn{7}{|l|}{ What to do if COVID-19 continues? } \\
\hline Follow the same precautions & $70(75.4)$ & $83(76.9)$ & $50(89.3)$ & $39(72.2)$ & & \\
\hline Return to usual work before COVID 19 & $2(2.4)$ & $6(5.6)$ & $0(0.0)$ & $0(0.0)$ & 13.9 & $0.030 *$ \\
\hline I don't know & $10(12.2)$ & 19(17.6) & $6(10.7)$ & $15(27.8)$ & & \\
\hline
\end{tabular}

Data are presented as n (\%), * significant, **High significant

\section{Discussion:}

COVID-19 epidemic in Egypt is one of the most challenging bio-disasters, both at national and international public health levels in the last century. Healthcare providers across different specialties are facing tremendous psychological stress during this pandemic. During the pandemic of $\mathrm{H} 1 \mathrm{~N} 1$, health-care providers felt unprotected, anxious, and exhausted while working in environments that carry a high risk of infection ${ }^{21}$.

Ophthalmologists are at a particular risk of virus transmission through contact or droplet routes 
during slit lamp examination ${ }^{22}$. In our present study, the overall prevalence of anxiety was $93.3 \%$, and depression was $72.7 \%$ respectively. A recent study was conducted in China during the pandemic of COVID-19, which reported an overall estimated prevalence of anxiety, depression, to be around 44.6, $50.4 \%$ respectively ${ }^{23,24}$.

The current study showed marked higher prevalence of depressive symptoms in comparison to the universal range. During the pandemic of severe acute respiratory syndrome (SARS) in Taiwan, the reported prevalence of psychiatric morbidity was about $75 \%$ using the Chinese Health Questionnaire ${ }^{23}$. In our study ophthalmologists aged $\leq 30$ years were at higher risk of anxiety than those aged $>30$ around $56 \%, 44 \%$ respectively, Ophthalmologists at Age $\leq 30$ years were at higher risk of depression than those at Age $>30$ around $54.3 \%, 45.7 \%$ respectively. There are reports on increased anxiety and depression symptoms in younger individuals, especially those in health $\operatorname{care}^{25}$. On the other hand the results were different from that reported in USA in response to a hypothetical influenza pandemic, which showed that age did not play a role in reporting stress during a pandemic ${ }^{26}$.

Females are more prone to psychological distress. Anxiety and depression symptoms were significantly reported among females (55\% and 53\% respectively). This is consistent with several studies ${ }^{27-28,24-25}$. Married participants experienced a markedly higher level of psychological distress, probably due to fear of transmitting the disease to more vulnerable family members. Different findings were reported in a study from Saudi Arabia ,Unmarried participants experienced a slightly higher level of psychological distress, probably due to the lack of social support and interpersonal communication ${ }^{29}$.

Symptoms of depression were high in residents compared to fellows and consultants. In general, graduate and postgraduate medical trainees may display some mental health concerns including depressive symptoms compared to more senior physicians ${ }^{30-31}$. This high risk of depressive symptoms in the fellows compared to residents and consultants might be due to the fact that they are usually in transition between residency and seniority. In addition, fellows usually have a higher workload and more frequent contact with patients compared to others. Further studies are definitely needed to ascertain the real causes behind this finding and whether fellows are always having higher risk of depressive symptoms ${ }^{29}$.

In this study, ophthalmologists were working long hours for several days were markedly at a high risk for anxiety and depression probably due to the more liability to be infected. Also anxiety and depression markedly increased in ophthalmologists who have been infected with COVID -19probably due to loneliness and financial problems related to the long period of isolation. Furthermore anxiety and depression markedly increased in ophthalmologists who knew a colleague in the same specialty infected with COVD-19 probably due to fear of facing the same fate.

\section{Strengths and Limitations of study:}

This study was conducted on critical group of physicians and we went in depth by asking about all work-related issues. But it also had some limitations like the convenience sampling technique chosen but it is difficult to apply sampling methods at this time because of the pandemic. Individuals without Internet and unable or unwilling to use smartphones or email could not be included in the study as face-to face interview was difficult to be done during the pandemic of COVID-19. Self-reporting has its biases as the participants may understand and interpret the questions differently, which makes it difficult to correctly assess the accuracy of the responses. 


\section{Conclusion:}

COVID-19 pandemic had a great effect on young aged, married and resident, who taken much precautions and who are previously infected or knew a colleague infected with COVID-19. The psychological needs for ophthalmologists in particular and health-care providers in general should be addressed appropriately during the pandemic. Effort should be made to established psychological support unit, especially for high-risk health-care providers.

\section{Ethics declarations}

\section{CONFLICT OF INTEREST}

Hadeer A. El Shebshery, Zeinab A. Kasemy, Faried M. Wagdy, Tharwat H.Mokbel, Abd-Almonem Alhessy, Dina Abd Elfattah, all authors have no conflicts of interest that are directly relevant to the content of this review.

FUNDING: No sources of funding were used to conduct this review.

Reviewer disclosures: No relevant financial or other relationships to disclose.

Declaration of interest: No financial affiliations or financial involvement with any organization or entity with a financial competing with the subject matter or materials discussed in the review.

\section{References:}

1. Torales J, O'Higgins M, Castaldelli-Maia JM, Ventriglio A. The outbreak of COVID-19 coronavirus and its impact on global mental health. Int J Soc Psychiatry. 2020 Jun;66(4):317320.

2. Republic of Egypt Ministry of Health, 2020;https://www.care.gov.eg/EgyptCare/Ind

3. Dong L, Bouey J. Public mental health crisis during COVID-19 pandemic, China. Emerg Infect Dis 2020;26.

4. Zhang Y, Ma ZF. Impact of the COVID-19 Pandemic on Mental Health and Quality of Life among Local Residents in Liaoning Province,
China: A Cross-Sectional Study. Int J Environ Res Public Health. 2020 Mar 31;17(7):2381.

5. Qiu J, Shen B, Zhao M, Wang Z, Xie B, Xu Y. A nationwide survey of psychological distress among Chinese people in the COVID-19 epidemic: Implications and policy recommendations. Gen Psychiatr 2020;33:e100213

6. Kang $\mathrm{L}^{1}$, Li Y, Hu S, Chen M, Yang C, Yang BX, et al. The mental health of medical workers in Wuhan, China dealing with the 2019 novel coronavirus. Lancet Psychiatry 2020;7:e14

7. Kang L, Ma S, Chen M, Yang J, Wang Y, Li R, Yao L, Bai H, Cai Z, Xiang Yang B, Hu S, Zhang K, Wang G, Ma C, Liu Z. Impact on mental health and perceptions of psychological care among medical and nursing staff in Wuhan during the 2019 novel coronavirus disease outbreak: A crosssectional study. Brain Behav Immun. 2020 Jul;87:11-17.

8. Van Doremalen N, Bushmaker T, Morris DH, Holbrook MG, Gamble A, Williamson BN, et al. Aerosol and surface stability of SARS-CoV-2 as compared with SARS-CoV-1. N Engl J Med 2020;382:1564-7.

9. Li JO, Lam DSC, Chen Y, Ting DSW. Novel coronavirus disease 2019 (COVID-19): The importance of recognising possible early ocular manifestation and using protective eyewear. $\mathrm{Br} \mathrm{J}$ Ophthalmol 2020;104:297-8

10. Tong T, Lai TS. The severe acute respiratory syndrome coronavirus in tears. $\mathrm{Br} \mathrm{J}$ Ophthalmol 2005 Mar;89(3):392..

11. Wu P, Duan F, Luo C, Liu Q, Qu X, Liang L, Wu K. Characteristics of Ocular Findings of Patients With Coronavirus Disease 2019 (COVID-19) in Hubei Province, China. JAMA Ophthalmol. 2020 May 1;138(5):575-578.

12. Seah IYJ, Anderson DE, Kang AEZ, Wang L, Rao P, Young BE, Lye DC, Agrawal R. Assessing 
Viral Shedding and Infectivity of Tears in Coronavirus Disease 2019 (COVID-19) Patients. Ophthalmology. 2020 Jul;127(7):977-979.

13.Xia J, Tong J, Liu M, Shen Y, Guo D. Evaluation of coronavirus in tears and conjunctival secretions of patients with SARS-CoV-2 infection. J Med Virol 2020 Jun;92(6):589-594.

14. Minocha A, Sim SY, Than J, Vakros G. Survey of ophthalmology practitioners in A\&E on current COVID-19 guidance at three Major UK Eye Hospitals. Eye (London, England) 2020 Jul;34(7):1243-1245.

15.Cheema M, Aghazadeh H, Nazarali S, Ting A, Hodges J, McFarlane A, Kanji JN, Zelyas N, Damji KF, Solarte C. Keratoconjunctivitis as the initial medical presentation of the novel coronavirus disease 2019 (COVID-19). Can J Ophthalmol. 2020 Aug;55(4):e125-e129.

16. Shigemura J, Ursano RJ, Morganstein JC, Kurosawa M, Benedek DM. Public responses to the novel 2019 coronavirus (2019-nCoV) in Japan: Mental health consequences and target populations. Psychiatry Clin Neurosci 2020;74:281-2.

17. Torales J, O'Higgins M, Castaldelli-Maia JM, Ventriglio A. The outbreak of COVID-19 coronavirus and its impact on global mental health. Int J Soc Psych 2020;20764020915212.

18. Spitzer RL, Kroenke K, Williams JB, Löwe B. A brief measure for assessing generalized anxiety disorder: the GAD-7. Arch Intern Med 2006;166(10):1092-7.

19. Kroenke K, Spitzer RL, Williams JB, Monahan P, Löwe B. Anxiety disorders in primary care: prevalence, impairment, comorbidity, and detection. Ann Intern Med 2007;146(5):317-25.

20. Kocalevent RD, Hinz A, Brahler E. Standardization of the depression screener patient health questionnaire (PHQ-9) in the general population. Gen Hosp Psychiatry 2013;35:551-5.
21. Matsuishi K, Kawazoe A, Imai H, Ito A, Mouri K, Kitamura N, Miyake K, Mino K, Isobe M, Takamiya S, Hitokoto H, Mita T. Psychological impact of the pandemic (H1N1) 2009 on general hospital workers in Kobe. Psychiatry Clin Neurosci. 2012 Jun;66(4):353-60.

22. Turgut B. Role of ophthalmologists in combating with the Coronavirus disease 2019. Adv Ophthalmol Vis Syst 2020;10:31-4..

23. Chong MY, Wang WC, Hsieh WC, Lee CY, Chiu NM, Yeh WC, et al. Psychological impact of severe acute respiratory syndromeon health workers in a tertiary hospital. The British $\mathrm{J}$ of Psychiatry 2004;185:127-33.

24. Lai J, Ma S, Wang Y, Cai Z, Hu J, Wei N, Wu J, Du H, Chen T, Li R, Tan H, Kang L, Yao L, Huang M, Wang H, Wang G, Liu Z, Hu S. Factors Associated With Mental Health Outcomes Among Health Care Workers Exposed to Coronavirus Disease 2019. JAMA Netw Open. 2020 Mar 2;3(3):e203976.

25. Al-Rabiaah A, Temsah MH, Al-Eyadhy AA, Hasan GM, Al-Zamil F, Al-Subaie S, et al. Middle East Respiratory Syndrome-Corona Virus (MERS-CoV) associated stress among medical students at a university teaching hospital in Saudi Arabia. J Infect Public Health 2020;13:687-91

26. Balicer RD, Omer SB, Barnett DJ, Everly GS Jr. Local public health workers' perceptions toward responding to an influenza pandemic. BMC Public Health. 2006 Apr 18;6:99.

27. Alexander J L, Dennerstein L, Kotz K, Richardson G. Women, anxiety and mood: A review of nomenclature, comorbidity and epidemiology. Expert Review of Neurotherapeutics, 2007;7(11):45-58.

28. Zhong L, Luo W, Li M, Zhang Q, Liu G, LiT, Li Y. Knowledge, attitudes, and practices towards COVID-19 among Chinese residents during the rapid rise period of the COVID-19 outbreak: A 
quick online cross-sectional survey. International

Journal of Biological Sciences,
2020;16(10):1745-1752.

29. Almater A, Tobaigy M, Younis A, Alaqeel M, Abouammoh M. Psychological effect of COVID-19 on ophthalmologists Middle East African Journal of Ophthalmology 2020;27:2.
30. Golob A, Beste LA, Stern M, Johnson K. Emotional distress among physician residents and fellows: An observational study oftrainees seeking counseling visits. Acad Psychiatry 2017;42:25-30.

31. Mousa OY, Dhamoon MS, Lander S, Dhamoon AS. The MD blues: Under-recognized depression and anxiety in medical trainees. PLoS One 2016;11:e0156554. 